\title{
Photodynamic therapy as a novel treatment for halitosis in adolescents: study protocol for a randomized controlled trial
}

Rubia Garcia Lopes, Camila Haddad Leal de Godoy, Alessandro Melo Deana, Maria Eugenia Simões Onofre de Santi, Renato Araujo Prates, Cristiane Miranda França, Kristianne Porta Santos Fernandes, Raquel Agnelli Mesquita-Ferrari and Sandra Kalil Bussadori

\begin{abstract}
Background: Halitosis is a common problem that affects a large portion of the population worldwide. The origin of this condition is oral in $90 \%$ and systemic in $10 \%$ of cases. The unpleasant odor is mainly the result of volatile sulfur compounds produced by Gram-negative bacteria. However, it has recently been found that anaerobic Gram-positive bacteria also produce hydrogen sulfide $\left(\mathrm{H}_{2} \mathrm{~S}\right)$ in the presence of amino acids, such as cysteine. Light, both with and without the use of chemical agents, has been used to induce therapeutic and antimicrobial effects. In photodynamic therapy, the antimicrobial effect is confined to areas covered by photosensitizing dye. The aim of the present study is to evaluate the antimicrobial effect of photodynamic therapy on halitosis in adolescents through the analysis of volatile sulfur compounds measured using gas chromatography and microbiological analysis of coated tongue.

Methods/Design: A quantitative clinical trial will be carried out involving 60 adolescents randomly divided into the following groups: group 1 will receive treatment with a tongue scraper, group 2 will receive photodynamic therapy applied to the posterior two-thirds of the dorsum of the tongue, and group 3 will receive combined treatment (tongue scraper and photodynamic therapy). Gas chromatography (OralChroma ${ }^{\mathrm{TM}}$ ) and microbiological analysis will be used for the diagnosis of halitosis at the beginning of the study. Post-treatment evaluations will be conducted at one hour and 24 hours after treatment. The statistical analysis will include the Shapiro-Wilk test for the determination of the distribution of the data. If normal distribution is demonstrated, analysis of variance followed by Tukey's test will be used to compare groups. The Kruskal-Wallis test followed by the Student-Newman-Keuls test will be used for data with non-normal distribution. Either the paired $t$-test or the Wilcoxon test will be used to compare data before and after treatment, depending on the distribution of the data.
\end{abstract}

Discussion: The results of this trial will determine the efficacy of using photodynamic therapy alone or in combination with a tongue scraper to treat bad breath in adolescents.

Trial registration: The protocol for this study was registered with Clinical Trials (registration number NCT02007993) on 10 December 2013.

Keywords: Halitosis, Photodynamic therapy, Adolescent

\footnotetext{
* Correspondence: sandra.skb@gmail.com

University Nove de Julho, Rua Vergueiro, 235, Liberdade, São Paulo, SP

01504-000, Brazil
}

\section{Biomed Central}

(c) 2014 Lopes et al.; licensee BioMed Central Ltd. This is an Open Access article distributed under the terms of the Creative Commons Attribution License (http://creativecommons.org/licenses/by/4.0), which permits unrestricted use, distribution, and reproduction in any medium, provided the original work is properly credited. The Creative Commons Public Domain Dedication waiver (http://creativecommons.org/publicdomain/zero/1.0/) applies to the data made available in this article, unless otherwise stated. 


\section{Background}

Halitosis is a term used to define an unpleasant odor that emanates from the mouth, stemming from either a local or systemic origin [1-3]. This common problem affects a large portion of the population worldwide and causes considerable embarrassment. Therefore, halitosis has a negative impact on social communication and quality of life [4]. The lack of standardization in the protocol for the diagnosis and treatment of halitosis hinders the comparison of data from epidemiological studies conducted in different countries and yet it is believed that $25 \%$ of the population are affected by this condition [5].

Studies on the etiology of halitosis report that $2 \%$ of cases stem from renal, metabolic, hepatic, endocrinological and gastrointestinal disorders (such as infection by Helicobacter pylori and intestinal blockage), and $8 \%$ are due to conditions of the respiratory system and conditions of the ears, nose and throat (ENT), such as acute tonsillitis, postnasal drip, sinusitis and tonsillolith. The majority of cases (80 to $90 \%$ ) are directly linked to conditions of the oral cavity, such as periodontal disease, coated tongue, poor oral hygiene, salivary abnormalities (change in $\mathrm{pH}$ and hyposialy), stomatitis, intra-oral neoplasm, pulp exposure, extraction wounds and crowding of the teeth [5-8].

Bad breath mainly stems from volatile sulfur compounds (VSCs) produced by the action of anaerobic Gram-negative bacteria (Fusobacterium nucleatum, Selenomonas, Treponema denticola, Prevotella intermedia, Tannerella forsythyia, Porphyromonas gingivalis, Bacteroides forsythus and Eubacterium) found in the oral cavity on substrates containing sulfur [9-11]. The VSCs produced by the metabolism of these bacteria are hydrogen sulfide $\left(\mathrm{H}_{2} \mathrm{~S}\right)$, found mainly on the dorsum of the tongue, methanethiol $\left(\mathrm{CH}_{3} \mathrm{SH}\right)$ in gingival pockets and dimethyl sulfide $\left(\mathrm{CH}_{3} \mathrm{SCH}_{3}\right)$, which has an extra-oral origin [12-15]. The concentration of these compounds is used as an indicator of halitosis $[3,16]$.

Recently, the anaerobic Gram-positive bacterium Solobacterium moorei (also known as Bulleidia moorei) has been associated with halitosis due to the production of $\mathrm{H}_{2} \mathrm{~S}$ in the presence of different supplements containing amino acids, especially cysteine $[17,18]$. Studies have demonstrated that the presence of these bacteria on the dorsum of the tongue, as well as in saliva and periodontal pockets, can lead to both halitosis and systemic problems such as complications during pregnancy, cardiovascular disease and chronic lower respiratory infection [19], which is considered the third most common cause of death [2,20-23].

\section{Detection}

Two main methods are used to evaluate halitosis: a subjective (organoleptic) evaluation and an objective evaluation (quantitative measure of VSCs, gas chromatography (GC) and monitor analysis) [24-27]. Studies comparing the efficacy of these methods report GC to be the most objective and efficacious method for the individual detection of $\mathrm{H}_{2} \mathrm{~S}, \mathrm{CH}_{3} \mathrm{SH}$ and $\mathrm{CH}_{3} \mathrm{SCH}_{3}$, allowing the evaluation of both the intensity of bad breath and its origin [5,15]. Indeed, GC is currently considered the gold standard for the detection of halitosis [11]. However, the majority of researchers have used a combination of both subjective and objective evaluations, whereas others have only used an organoleptic evaluation due to its ease of execution and low cost [24]. Halitosis can be analyzed using a sulfide monitor, such as the Halimeter (Interscan Corporation, Chatsworth, California, United States) [3,4,26-28], which determines the total amount of VSCs in parts per billion (ppb) under normal conditions.

\section{Photodynamic therapy}

Photodynamic therapy (PDT) was discovered in 1900 by Oskar Raab and Hermann von Tappeiner. In the 1970s, PDT began to be used for the treatment of cancer. Recently, antimicrobial PDT has been used as a treatment option for localized infections [29]. PDT involves the use of a non-toxic light-sensitive photosensitizer combined with visible light at the appropriate wavelength to coincide with the absorption spectrum of the photosensitizer, which reaches a state of excitation after absorbing the photons, reacting with the oxygen in the medium to form reactive oxygen species. This phototoxic reaction induces the destruction of bacterial cells. The antimicrobial effect is confined to areas covered by the light-activated photosensitizer, quickly acting on the target organisms when the appropriate energy dose and output power are used [9,29-33]. According to Wainwright [34], bacterial resistance to PDT is unlikely, as the singlet oxygen and free radicals formed interact with different bacterial cell structures and different metabolic pathways [32,33].

The conventional treatment of halitosis related to oral conditions consists of the chemical reduction of microorganisms with a mouthwash, such as $0.2 \%$ chlorhexidine, essential oils, triclosan and hydrogen peroxide, the mechanical removal of nutrients with a tongue scraper or brush, the masking of odor with chewing gum, mints and breath spray, and the transformation of VSCs using zinc plus chlorhexidine [2,5,10,12,35-37]. However, the irregular characteristics of the surface of the dorsum of the tongue make the adequate reduction in bacterial a particular challenge [2,36,38].

Considering the scarcity of studies addressing the effect of PDT on tongue biofilm, the aim of the present study was to evaluate the effectiveness of PDT on the dorsum of the tongue in adolescents with halitosis by an analysis of VSCs and microbiological analysis of the tongue. 


\section{Methods/Design}

This study will be carried out in compliance with regulatory norms governing research involving human subjects. Approval was obtained from the Human Research Ethics Committee of University Nove de Julho (Brazil) under process number $037315 / 2013$, and the study is registered with the United States National Institutes of Health (Clinical Trials.gov registration number: NCT02007993). The guardians of the participants will be informed regarding the procedures and will sign a statement of informed consent authorizing the participation of their sons and daughters in compliance with Resolution 196/96 of the Brazilian National Health Board.

Male and female adolescents enrolled at the dental clinic of the university will be recruited for the study. Those aged between 13 and 18 years, with a diagnosis of halitosis and OralChroma ${ }^{\text {Tw }}$ results of $\mathrm{H}_{2} \mathrm{~S} \geq 112 \mathrm{ppb}$ during the cysteine challenge $[11,15,39,40]$ will be included. The exclusion criteria will be [41] dentofacial anomalies, currently undergoing orthodontic or orthopedic treatment, current use of a removable appliance, implant or dentures, periodontal disease, teeth with carious lesions, currently undergoing cancer treatment, diabetes mellitus, systemic (gastrointestinal, renal or hepatic disorder) conditions, ear, nose or throat conditions, respiratory conditions, antibiotic therapy in the previous month, current pregnancy [5] or hypersensitivity to the photosensitizer. As this is a randomized clinical trial, the recommendations of the Consolidated Standards of Reporting Trials (CONSORT) will be used to ensure greater transparency and quality (Figure 1).

The subjects selected will be randomly allocated to three groups (Table 1). All individuals will be submitted to evaluations with OralChroma ${ }^{\text {Tx }}$ before and after treatment.

\section{Microbiological analysis}

Microbiological analyses of coated tongue will be performed before and after treatment using a 1- $\mu \mathrm{l}$ inoculation loop for the collection of biofilm samples from the dorsum of the tongue. The samples will be transferred to $1.5-\mathrm{ml}$ vials with reduced transport fluid and placed in a vortex mixer (Prolab, São Paulo - Brazil) for approximately 30 seconds for homogenization. Ten-fold serial dilution will be prepared in $180 \mu \mathrm{l}$ of sterile phosphate buffered saline (Probac, São Paulo - Brazil) and aliquots of $10^{-2}, 10^{-3}, 10^{-4}$ and $10^{-5}$ will be transferred to plates with brain-heart infusion agar (Probac, São Paulo - Brazil). As the main bacteria responsible for the production of VSCs are Gram-negative, the plates will be incubated in anaerobic jar for 72 hours at $37^{\circ} \mathrm{C}$, following by the quantification of colony-forming units $[10,42]$.

\section{Halitosis detection}

The literature describes a number of methods for measuring halitosis, such as an organoleptic evaluation of the

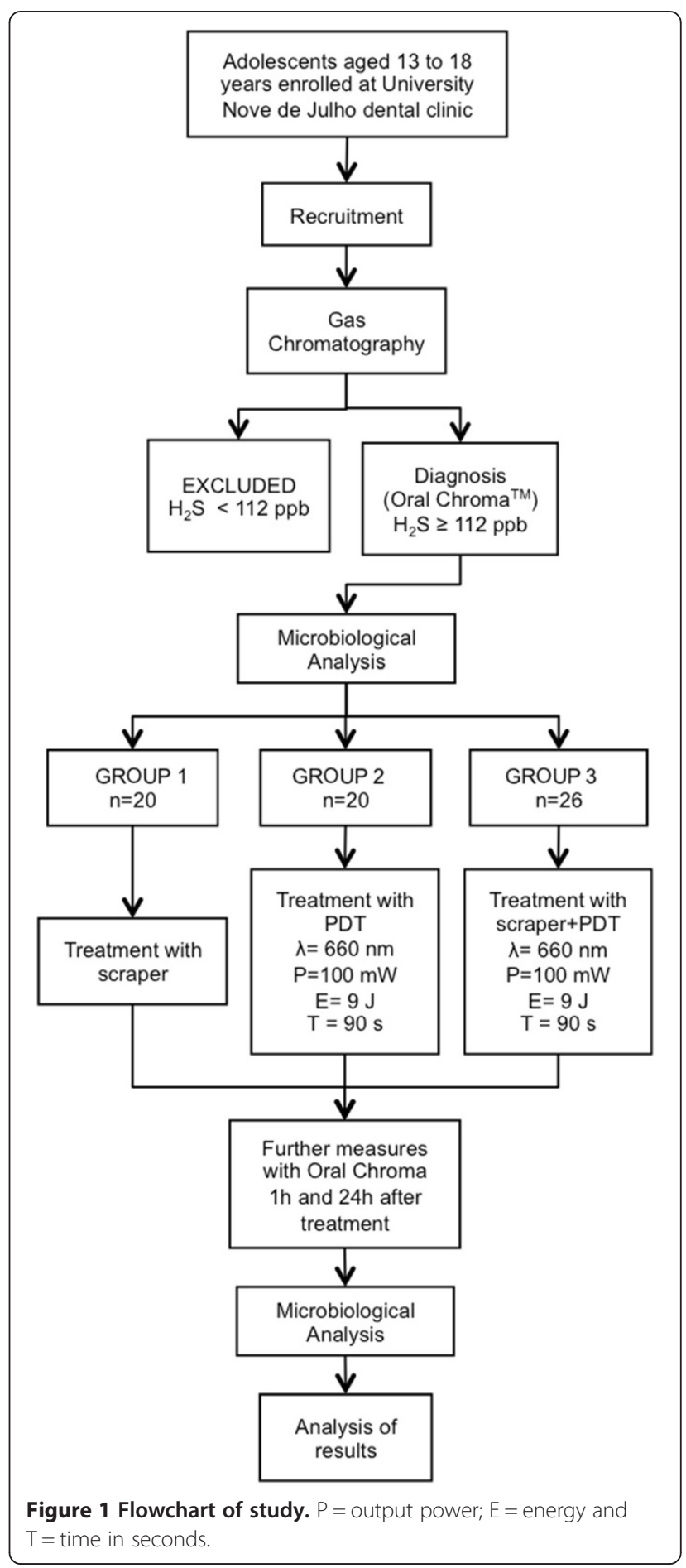

air emanating from the oral cavity $[16,26]$ using a sulfide monitor $[16,25,43]$ or GC $[11,43,44]$. However, it has been demonstrated that the organoleptic test can be influenced by the olfactory capacity and emotional state of the examiner, as well as climatic conditions [3]. Therefore, the portable OralChroma ${ }^{\mathrm{Tw}}$ device Abilit Corporation, Chuo-ku, Osaka - Japan) will be employed. This device uses a highly sensitive gas semiconductor sensor. 
Table 1 Summary of experimental conditions

\begin{tabular}{cccc}
\hline Group & Halitosis & Treatment \\
\hline 1 & $\mathrm{H}_{2} \mathrm{~S} \geq 112 \mathrm{ppb}$ & Tongue scraper \\
2 & $\mathrm{H}_{2} \mathrm{~S} \geq 112 \mathrm{ppb}$ & \multicolumn{2}{c}{ PDT } \\
& & $\mathrm{E}=9 \mathrm{~J}$ & $\mathrm{~T}=90 \mathrm{~s}$ \\
3 & $\mathrm{SH}_{2} \geq 112 \mathrm{ppb}$ & Tongue scraper + PDT \\
& & $\mathrm{E}=9 \mathrm{~J}$ & $\mathrm{~T}=90 \mathrm{~s}$ \\
\end{tabular}

$\mathrm{H}_{2} \mathrm{~S}=$ hydrogen sulfide; $\mathrm{ppb}=$ part per billion; $\mathrm{PDT}=$ photodynamic therapy; $\mathrm{E}=$ energy; $\mathrm{T}=$ time in seconds.

The participant will first rinse with cysteine (Fórmula \& Ação, São Paulo - Brazil) for one minute (cysteine $10 \mathrm{mM}-16 \mathrm{mg}$ of cysteine in $100 \mathrm{ml}$ of distilled water $16 \% \mathrm{mg})$. A syringe will be placed in the participant's mouth with the plunger completely inserted. The participant will close his or her mouth, breathe through the nose and remain still with the mouth closed for one minute. The participant will be instructed not to touch the tip of the syringe with his or her tongue. The plunger will then be withdrawn, pushed back in to empty the air into the participant's mouth and will be withdrawn again to fill the syringe with the breath sample. The tip of the syringe will be cleaned to remove saliva and a gas injection needle will be placed on the syringe. The plunger will be adjusted to $0.5 \mathrm{ml}$ and the contents will be injected into the input of the device in a single motion (Figure 2) [15].

\section{Analysis of VSCs}

OralChroma $^{\text {тм }}$ (Abilit Corporation) was developed in Japan for the individual determination of $\mathrm{H}_{2} \mathrm{~S}, \mathrm{CH}_{3} \mathrm{SH}$ and $\mathrm{CH}_{3} \mathrm{SCH}_{3}$, allowing for the evaluation of both the intensity of bad breath and its origin $[5,11,15] . \mathrm{H}_{2} \mathrm{~S}$ originates mainly from bacteria on the dorsum of the tongue. Values greater than $112 \mathrm{ppb}$ indicate halitosis. $\mathrm{CH}_{3} \mathrm{SH}$ is found in greater concentration in periodontal pockets. Values up to $26 \mathrm{ppb}$ are considered normal. Periodontal disease typically results in a high $\mathrm{CH}_{3} \mathrm{SH}: \mathrm{H}_{2} \mathrm{~S}$ ratio $(>3: 1) . \mathrm{CH}_{3} \mathrm{SCH}_{3}$ may have a periodontal or systemic (intestine, liver or lung) origin and may also be temporarily caused by the ingestion of certain foods and beverages. The distinction between $\mathrm{CH}_{3} \mathrm{SCH}_{3}$ of an oral or systemic origin can be made through the comparison of the results of the halimetric (OralChroma ${ }^{\mathrm{m}}$ ) with and without a cysteine challenge. The perception threshold for $\mathrm{CH}_{3} \mathrm{SCH}_{3}$ is very low (8 ppb). Other non-VSC odors may appear in a peak prior to the theoretical first peak, which is $\mathrm{H}_{2} \mathrm{~S}$ [15].

To maximize the standardization of the readings, the exam will be carried out in the morning and the participants will be instructed to avoid the ingestion of foods with garlic, onion or strong spices, as well as the consumption of alcohol and the use of an antiseptic mouthwash. On the morning of the exam, more than two hours should have passed since any food intake and the participants are to abstain from coffee, hard candy, chewing gum, oral hygiene products and personal care items containing fragrances (aftershave, deodorant, perfume and creams). Brushing will be performed with water alone $[27,45]$.

\section{Photodynamic therapy}

The THERAPY XT-ES ${ }^{\text {mix }}$ (DMC ABC Medical and Dental Equipment, São Paulo, Brazil) with a red $(660 \mathrm{~nm})$ and infrared $(810 \mathrm{~nm})$ laser and a fine tip (for regions of difficult access) will be used. Only the volunteer and operator will be present at the time of PDT and both will be wearing protective eyewear. The active point of the laser will be covered with disposable clear plastic wrap (PVC)

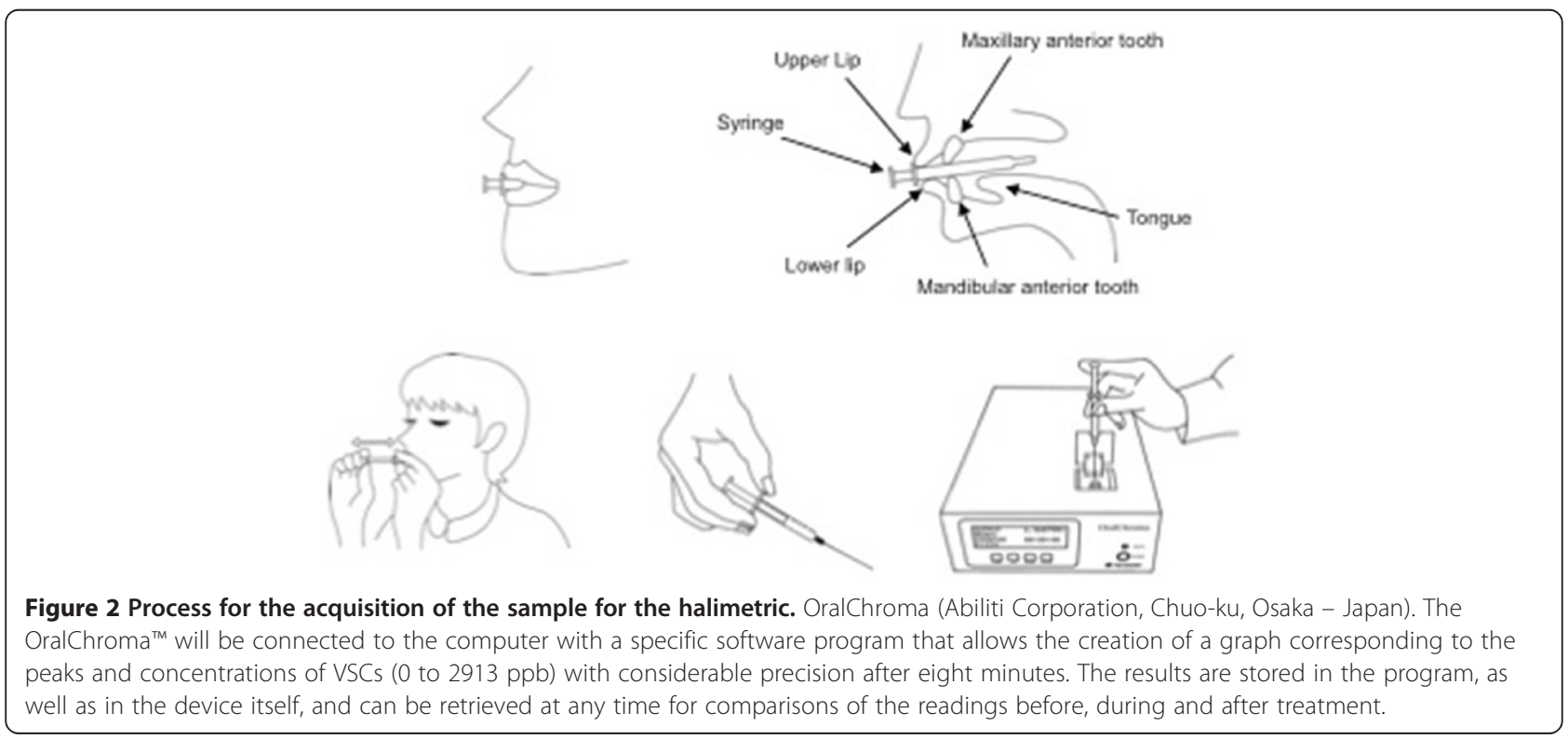


for hygiene purposes and to avoid cross-contamination. The operator will use the appropriate clothing.

A single session of PDT will be performed with the Chimiolux $^{\text {tw }}$ methylene blue photosensitizer (DMC ABC Medical and Dental Equipment, São Paulo, Brazil) at a concentration of $0.005 \%(165 \mu \mathrm{m})$ applied to the middle and posterior thirds of the dorsum of the tongue. After five minutes of pre-irradiation time for incubation, the excess will be removed with an aspirator to maintain the surface moist with the photosensitizer alone (without the use of water). A total of six points will be irradiated (Figure 3). Based on studies developed for the treatment of periodontal disease with PDT [46-52] and a previous pilot study [53], the device will be calibrated with a wavelength of $660 \mathrm{~nm}$, power output of $100 \mathrm{~mW}$, fluency of $320 \mathrm{~J} / \mathrm{cm}^{2}$, irradiance of $3537 \mathrm{~mW} / \mathrm{cm}^{2}$ and an energy dose of 9 joules for 90 seconds per point in groups 2 and 3. The punctual application method will be used with the conventional tip in contact with the tongue (Table 2).

\section{Tongue scraping intervention}

A Halicare ${ }^{\mathrm{Tt}}$ tongue scraper (Odomed, São Paulo, Brazil) will be used for the removal of biofilm. The participant will be instructed to divide the tongue into two parts and scrape each side 10 times (Figure 4).

\section{Calculation of sample size}

The error was established as err $=\left|\overline{x_{1}}-\overline{x_{2}}\right|$, in which $\overline{x_{1}}$ and $\overline{x_{2}}$ are the means of groups 1 and 2 . Assuming both

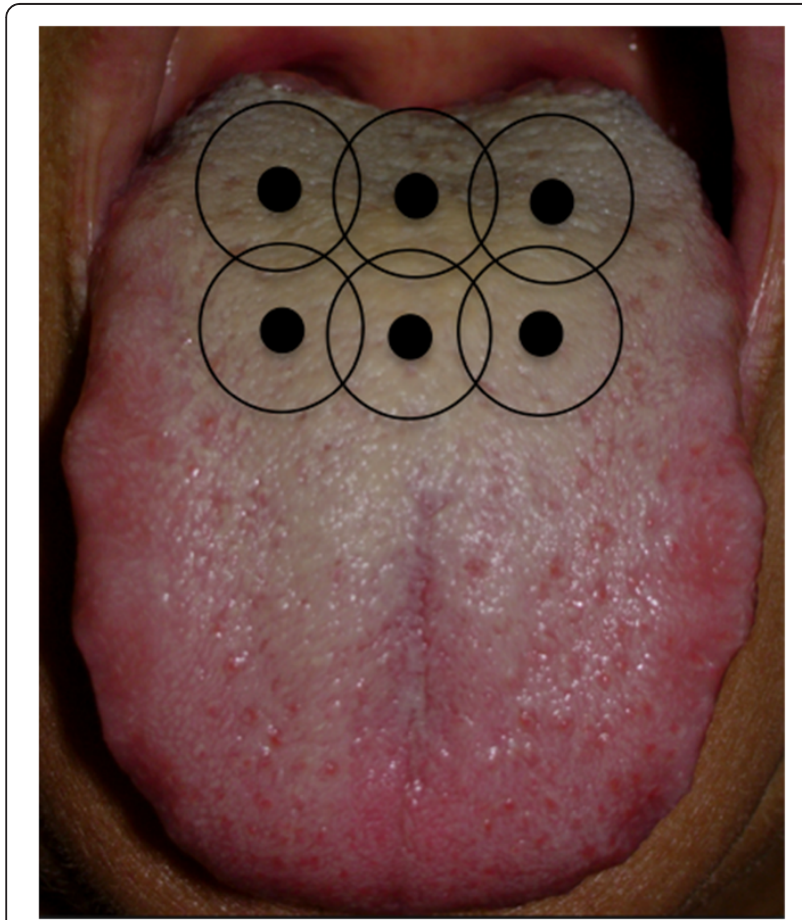

Figure 3 Points of photodynamic therapy application.
Table 2 Parameters of laser

\begin{tabular}{lc}
\hline Parameter & Red laser \\
\hline Center wavelength $(\mathrm{nm})$ & 660 \\
Spectral bandwidth $(\mathrm{FWHM})(\mathrm{nm})$ & 5 \\
Operating mode & Continuous wave \\
Average radiant power $(\mathrm{mW})$ & 100 \\
Polarization & Random \\
Aperture diameter $(\mathrm{cm})$ & 0.094 \\
Irradiance at aperture $\left(\mathrm{mW} / \mathrm{cm}^{2}\right)$ & 3537 \\
Beam profile & Multimode \\
Beam spot size at target $\left(\mathrm{cm}^{2}\right)$ & 0.02827 \\
Irradiance at target $\left(\mathrm{mW} / \mathrm{cm}^{2}\right)$ & 3537 \\
Exposure duration $(\mathrm{s})$ & $90 / 120$ \\
Radiant exposure $\left(\mathrm{J} / \mathrm{cm}^{2}\right)$ & $320 / 428$ \\
Radiant energy $(\mathrm{J})$ & $9 / 12$ \\
Number of points irradiated & 9 \\
Area irradiated $\left(\mathrm{cm}^{2}\right)$ & 0.254 \\
Application technique & Contact \\
Number and frequency of treatment sessions & 1 session \\
Total radiant energy $(\mathrm{J})$ & $81 / 108$ \\
\hline
\end{tabular}

samples as having the same size $\left(\mathrm{n}_{1}=\mathrm{n}_{2}\right)$, the sample size is obtained from the following equation:

$$
n_{1}=n_{2}=\frac{e r r}{Z \sqrt{\sigma_{1}^{2}+\sigma_{2}^{2}}}
$$

in which $\sigma_{1}^{2}$ and $\sigma_{1}^{2}$ are the variances in groups 1 and 2, respectively. As more than two groups will be studied, the decision was made to employ the largest error found in the literature [54] to estimate the sample size. Assuming all groups as having normal or approximately normal distribution, and that the sample will be large enough for a significance level of $\alpha=0.05$, the $Z$ value was determined to be 1.96 . However, for the sample size, the test power was established as 1- $\beta=0.80$. In case the hypothesis of normality in the samples was rejected, the sample size was corrected by $5 \%$. Based on the experimental groups in the study by Tsai et al. [54] it was determined that each group should contain 26 participants $(\mathrm{n}=26)$.

\section{Outcome measures}

Only participants with $\mathrm{H}_{2} \mathrm{~S} \geq 112 \mathrm{ppb}, \mathrm{CH}_{3} \mathrm{SH} \leq 26 \mathrm{ppb}$ and $\mathrm{CH}_{3} \mathrm{SCH}_{3} \leq 8 \mathrm{ppb}$ will be part of the research, which limits participation to individuals with halitosis caused by coated tongue alone. Immediately after treatment, a second halimetry test will be performed and the results will be analyzed. 


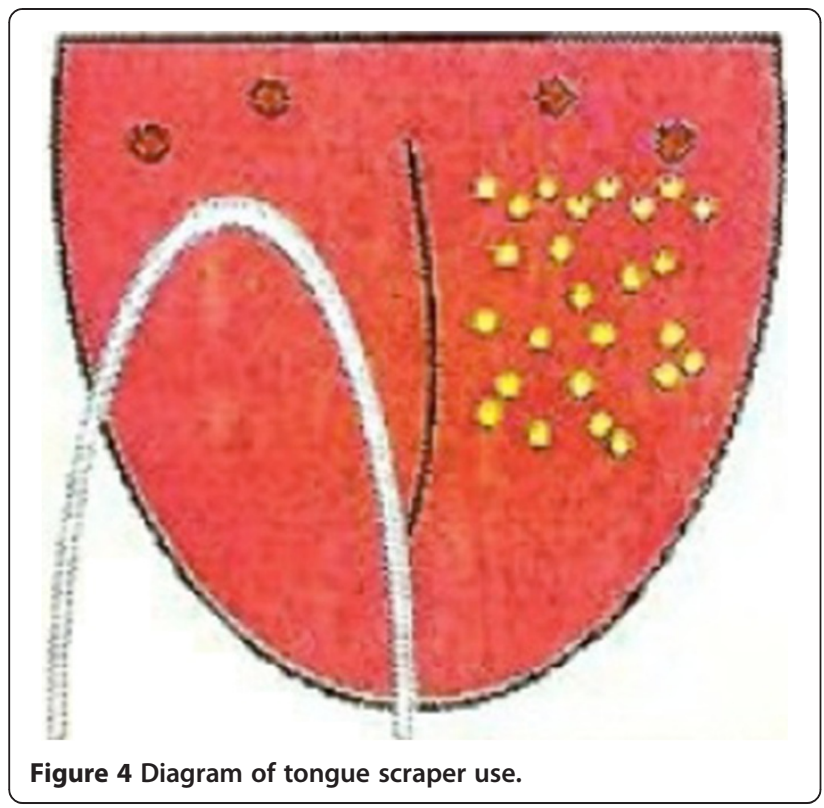

\section{Hypothesis}

Our null hypothesis is that there will be no change in halitosis following the use of PDT. Our experimental hypothesis is that there will be a reduction in halitosis following the use of PDT alone or in combination with a tongue scraper.

\section{Organization and statistical analysis of data}

The Shapiro-Wilk test will be used to determine the distribution of the halimetricdata. If the data presents with normal distribution, analysis of variance (ANOVA) followed by the Tukey test will be used to evaluate the correlation between each of the proposed treatments and halitosis. The paired $t$-test will be used to compare the data before and after each treatment and determine whether the treatments reduced the degree of halitosis. The Kruskal-Wallis test followed by the StudentNewman-Keuls test will be used for data with nonnormal distribution, and the Wilcoxon test will be used to analyze the data before and after each treatment. Microbiological data presents with log-normal distribution and will therefore be analyzed using the methods described for data with normal distribution. A significance level of $\alpha=0.05$ will be used.

\section{Discussion}

The main objective of the proposed study is to evaluate the effect of PDT with and without the use of a tongue scraper for the treatment of halitosis in adolescents. This objective has two aspects: the evaluation of VSC levels before and after treatment through a quantitative analysis of $\mathrm{H}_{2} \mathrm{~S}$ using $\mathrm{GC}$, and a microbiological analysis of the effect of PDT on coated tongue. The findings are expected to provide convincing evidence that PDT is more effective for the treatment of halitosis.

In the literature, the treatment of halitosis is performed using a tongue scraper with or without a mouthwash [2], which leads to a small, long-term reduction in the amount of bacteria on the tongue [38]. Thus, daily oral hygiene is needed to maintain a low level of bacterial proliferation. As the penetration of light and spreading of the photosensitizer do not seem to be affected by the posterior papillae of the tongue, treatment with PDT is promising and may achieve satisfactory results, especially when combined with conventional treatment.

\section{Trial status}

The authors are currently recruiting participants. It begun on March of 2014 and we pretend to go until August of 2015.

\section{Abbreviations}

$\mathrm{CH}_{3} \mathrm{SCH}_{3}$ : Dimethyl sulfide; $\mathrm{CH}_{3} \mathrm{SH}$ : Methanethiol; GC: Gas chromatography; $\mathrm{H}_{2} \mathrm{~S}$ : Hydrogen sulfide; PDT: Photodynamic therapy; VSC: Volatile sulfur compounds.

\section{Competing interests}

The authors declare that they have no competing interests.

\section{Authors' contributions}

RGL participated in the conception and design of the study, data collection and drafting of the present manuscript. CHLG helped draft the manuscript and participated in the data collection. AMD performed the statistical analysis. RAP contributed to the design of the study. MESOS, CMF, KPSF and RAMF critically reviewed the manuscript for intellectual content. SKB conceived the study and coordination and helped draft the manuscript. All authors read and approved the final manuscript.

\section{Acknowledgements}

This study was supported by Fundação de Amparo a Pesquisa do Estado de São Paulo (FAPESP; number 2013/13032-8). The authors gratefully acknowledge the University Nove de Julho for its technological support.

Received: 1 August 2014 Accepted: 7 October 2014

Published: 14 November 2014

\section{References}

1. Shimura M, Watanabe S, Iwakura M, Oshikiri Y, Kusumoto M, Ikawa K, Sakamoto S: Correlation between measurements using a new halitosis monitor and organoleptic assessment. J Periodontol 1997, 68:1182-1185.

2. Quirynen M, Avontroodt P, Soers C, Zhao H, Pauwels M, Van Steenberghe D: Impact of tongue cleansers on microbial load and taste. J Clin Periodontol 2004, 31:506-510.

3. Rosenberg M, McCulloch CA: Measurement of oral malodor: current methods and future prospects. J Periodontol 1992, 63:776-782.

4. Kizhner $V, X u D$, Krespi YP: A new tool measuring oral malodor quality of life. Eur Arch Otorhinolaryngol 2011, 268:1227-1232.

5. Bollen CML, Beikler T: Halitosis: the multidisciplinary approach. Int J Oral Sci 2012, 4:55-63.

6. Amir E, Shimonov R, Rosenberg M: Halitosis in children. J Pediatr 1999, 134:338-343.

7. Dal Rio AC, Passos CAC, Nicola JH, Nicola EMD: CO2 laser cryptolysis by coagulation for the treatment of halitosis. Photomed Laser Surg 2006, 24:630-636.

8. Marocchio LS, Da Conceição MD, Tárzia O: Tongue coating removal: comparison of the efficiency of three techniques. RGO 2009, 57:443-448.

9. Liu P-F, Zhu W-H, Huang C-M: Vaccines and photodynamic therapies for oral microbial-related diseases. Curr Drug Metab 2009, 10:90-94. 
10. Raangs $G$, Winkel $E$, Van Winkelhoff $A$ : In vitro antimicrobial effects of two antihalitosis mouth rinses on oral pathogens and human tongue microbiota. Int J Dent Hyg 2013, 11:203-207.

11. Salako NO, Philip L: Comparison of the use of the Halimeter and the Oral Chroma $^{\text {TM }}$ in the assessment of the ability of common cultivable oral anaerobic bacteria to produce malodorous volatile sulfur compounds from cysteine and methionine. Med Princ Pr 2011, 20:75-79.

12. Tolentino EDS, Chinellato LEM, Tarzia O: Saliva and tongue coating $\mathrm{pH}$ before and after use of mouthwashes and relationship with parameters of halitosis. J App/ Oral Sci 2011, 19:90-94.

13. Calil CM, Marcondes FK: Influence of anxiety on the production of oral volatile sulfur compounds. Life Sci 2006, 79:660-664.

14. Springfield J, Suarez F, Majerus G, Lenton P, Furne J, Levitt M: Spontaneus fluctuations in the concentrations of oral sulfur-containing gases. J Dent Res 2001, 80:1441-1444.

15. Tangerman A, Winkel EG: The portable gas chromatograph OralChroma ${ }^{\mathrm{TM}}$ : a method of choice to detect oral and extra-oral halitosis. J Breath Res 2008, 2:17010.

16. Rosenberg M, Kulkarni G, Bosy A, McCulloch C: Reproductibility and sensitivity of oral malodor measurements with a portable sulfide monitor. J Dent Res 1991, 70:1436-1440.

17. Tanabe S, Grenier D: Characterization of volatile sulfur compound production by Solobacterium moorei. Arch Oral Biol 2012, 57:1639-1643.

18. Haraszthy VI, Gerber D, Clark B, Moses P, Parker C, Sreenivasan PK, Zambon $J$ J: Characterization and prevalence of Solobacterium moorei associated with oral halitosis. J Breath Res 2008, 2:017002

19. Silvestri L, Weir I, Gregori D, Taylor D, Van Saene J, Van Saene H: Effectiveness of oral chlorhexidine on nosocomial pneumonia, causative microorganisms and mortality in critically ill patients: a systematic review and meta-analysis. Minerva Anestesiol 2014, 80:805-820.

20. Christensen G: Why clean your tongue? J Am Dent Assoc 1998, 129:1605-1607.

21. Tarzia O: Halitose: Um Desafio Que Tem Cura. 1st edition. São Paulo: Editora de Publicações Biomédicas LTDA; 2003.

22. Tanaka M, Yamamoto Y, Kuboniwa M, Nonaka A, Nishida N, Maeda K: Contribution of periodontal pathogens on tongue dorsa analyzed with real-time PCR to oral malodor. Microbes Infect 2004, 6:1078-1083.

23. Bansal $M$, Khatri $M$, Taneja $V$ : Potential role of periodontal infection in respiratory diseases - a review. J Med Life 2013, 6:244-248.

24. Kara C, Demir T, Orbak R, Tezel A: Effect of Nd: YAG laser irradiation on the treatment of oral malodour associated with chronic periodontitis. Int Dent J 2008, 58:151-158.

25. Kara C, Tezel A, Orbak R: Effect of oral hygiene instruction and scaling on oral malodour in a population of Turkish children with gingival inflammation. Int J Paediatr Dent 2006, 16:399-404.

26. Rosenberg M: Bad breath, diagnosis and treatment. Univ Tor Dent J 1990, 3:7-11.

27. Donaldson AC, Riggio MP, Rolph HJ, Bagg J, Hodge PJ: Clinical examination of subjects with halitosis. Oral Dis 2007, 13:63-70.

28. Furne J, Majerus G, Lenton P, Springfield J, Levitt DG, Levitt MD: Comparison of volatile sulfur compound concentrations measured with a sulfide detector vs. gas chromatography. J Dent Res 2002, 81:140-143.

29. Dai T, Fuchs BB, Coleman JJ, Prates RA, Astrakas C, St Denis TG, Ribeiro MS Mylonakis E, Hamblin MR, Tegos GP: Concepts and principles of photodynamic therapy as an alternative antifungal discovery platform. Front Microbiol 2012, 3:120.

30. Pervaiz S, Olivo M: Art and science of photodynamic therapy. Clin Exp Pharmacol Physiol 2006, 33:551-556.

31. Fontana CR, Abernethy AD, Som S, Ruggiero K, Doucette S, Marcantonio RC, Boussios Cl, Kent R, Goodson JM, Tanner AC, Soukos NS: The antibacterial effect of photodynamic therapy in dental plaque-derived biofilms. J Periodontal Res 2009, 44:751-759.

32. Hope C, Wilson M: Induction of lethal photosensitization in biofilms using a confocal scanning laser as the excitation source. J Antimicrob Chemother 2006, 57:1227-1230.

33. Wilson M: Lethal photosensitisation of oral bacteria and its potential application in the photodynamic therapy of oral infections. Photochem Photobiol Sci 2004, 3:412-418.

34. Wainwright M: Photodynamic antimicrobial chemotherapy (PACT) J Antimicrob Chemother 1998, 42:13-28.
35. Saad S, Greenman J, Shaw H: Comparative effects of various commercially available mouthrinse formulations on oral malodor. Oral Dis 2011, 17:180-186

36. Quirynen M, Mongardini C, Van Steenberghe D: The effect of a 1-stage full-mouth disinfection on oral malodor and microbial colonization of the tongue in periodontitis: a pilot study. J Periodontol 1998, 69:374-382

37. Saad S, Hewett K, Greenman J: Effect of mouth-rinse formulations on oral malodour processes in tongue-derived perfusion biofilm model. J Breath Res 2012, 6:016001.

38. Collins LM, Dawes $C$ : The surface area of the adult human mouth and thickness of the salivary film covering the teeth and oral mucosa. J Dent Res 1987, 66:1300-1302.

39. Aizawa F, Kishi M, Moriya T, Takahashi M, Inaba D, Yonemitsu M: The analysis of characteristics of elderly people with high VSC level. Oral Dis 2005, 11(Suppl 1):80-82.

40. Pham T, Ueno M, Zaitsu T, Takehara S, Shinada K, Lam P, Kawaguchi Y Clinical trial of oral malodor treatment in patients with periodontal diseases. J Periodont Res 2011, 46:722-729.

41. Casemiro LA, Martins CHG, De Carvalho TC, Panzeri H, Lavrador MAS, Pires-de-Souza FDCP: Effectiveness of a new toothbrush design versus a conventional tongue scraper in improving breath odor and reducing tongue microbiota. J App/ Oral Sci 2008, 16:271-274.

42. Saad S, Greenman J: Tongue biofilm areal density and tongue coating index. J Breath Res 2008, 2:017008.

43. Motta LJ, Bachiega JC, Guedes CC, Laranja LT, Bussadoril SK: Association between halitosis and mouth breathing in children. Clinics 2011 66:939-942

44. Vandekerckhove B, Van den Velde S, De Smit M, Dadamio J, Teughels W, Van Tornout M, Quirynen M: Clinical reliability of non-organoleptic oral malodour measurements. J Clin Periodontol 2009, 36:964-969.

45. Quirynen M, Dadamio J, Van den Velde S, De Smit M, Dekeyser C, Van Tornout M, Vandekerckhove B: Characteristics of 2000 patients who visited a halitosis clinic. I Clin Periodontol 2009, 36:970-975.

46. Berakdar M, Callaway A, Eddin MF, Ross A, Willershausen B: Comparison between scaling-root-planing (SRP) and SRP / photodynamic therapy: six-month study. Head Face Med 2012, 8:12

47. Braun A, Dehn C, Krause F, Jepsen S: Short-term clinical effects of adjunctive antimicrobial photodynamic therapy in periodontal treatment: a randomized clinical trial. J Clin Periodontol 2008, 35:877-884.

48. Dilsiz A, Canakci V, Aydin T: Clinical effects of potassium-titanylphosphate laser and photodynamic therapy on outcomes of treatment of chronic periodontitis: a randomized controlled clinical trial. J Periodontol 2013, 84:278-286.

49. Giannelli M, Formigli L, Lorenzini L, Bani D: Combined photoablative and photodynamic diode laser therapy as an adjunct to non-surgical periodontal treatment: a randomized split-mouth clinical trial. J Clin Periodontol 2012, 39:962-970.

50. Lui J, Corbet E, Jin L: Combined photodynamic and low-level laser therapies as an adjunct to nonsurgical treatment of chronic periodontitis. J Periodontal Res 2011, 46:89-96.

51. Lulic M, Leiggener Gl, Salvi GE, Ramseier CA, Mattheos N, Lang NP. One-year outcomes of repeated adjunctive photodynamic therapy during periodontal maintenance: a proof-of-principle randomized controlled clinical trial. J Clin Periodontol 2009, 36:661-666.

52. Polansky R, Haas M, Heschl A, Wimmer G: Clinical effectiveness of photodynamic therapy in the treatment of periodontitis. J Clin Periodontol 2009, 36:575-580.

53. Lopes RG, Santi MESO, Franco BE, Deana AM, Prates RA, França CM, Fernandes KPS, Mesquita-Ferrari RA, Bussadori SK: Photodynamic therapy as novel treatment for halitosis in adolescents: a case series study. J Laser Med Sci 2014, 5:146-152.

54. Tsai C-C, Chou H-H, Wu T-L, Yang Y-H, Ho K-Y, Wu Y-M, Ho Y-P: The levels of volatile sulfur compounds in mouth air from patients with chronic periodontitis. J Periodontal Res 2008, 43:186-193.

doi:10.1186/1745-6215-15-443

Cite this article as: Lopes et al:: Photodynamic therapy as a nove treatment for halitosis in adolescents: study protocol for a randomized controlled trial. Trials 2014 15:443. 